\title{
Effect of Technological Developments on Ethical Position of Translator
}

\author{
Luis Miguel Dos Santos ${ }^{1}$ \\ ${ }^{1}$ Faculty of International Tourism and Management, School of Continuing Studies, City University of Macau, \\ Macau \\ Correspondence: Luis Miguel Dos Santos, Faculty of International Tourism and Management, School of \\ Continuing Studies, City University of Macau, Macau. E-mail: luismigueldossantos@yahoo.com
}

Received: July 6, 2016 Accepted: July 26, 2016 Online Published: August 28, 2016

doi:10.5539/ells.v6n3p42 URL: http://dx.doi.org/10.5539/ells.v6n3p42

\begin{abstract}
The objective of this essay is to examine and discuss the effect of recent technological developments on ethical position of translator. The associations between technology and the process of translation is a section of the greater discussion regarding the impacts that technology has on language. Presently, the career of interpreting and translating and its different branches, for example localization, are alleged to be under amplified threat from technological developments and practices such as crowdsourcing (Baker \& Maier, 2011). The importance currently assigned to the effects of recent technology on the ethical position of the translator emanates from the fact that there are currently several emergent translation technologies, for example, collaborative translation management systems, translation memories and data-based machine translation, which transform the social links, professional views and thought patterns of the translator (Pym, 2001). In addition to examining the relationship between technology and translation, this essay will also assess the ethical questions posed by technology for translators. At the end of the essay are a conclusive summary of the entire discussion and an alphabetical list of the references cited herein.
\end{abstract}

Keywords: machine translation, technology in translation, translation ethics

\section{Introduction}

\subsection{Technology and Translation}

For many years, technology has restructured the theory and practice of translation in different ways. While translators were conventionally expected to work solely through the use of dictionaries and their knowledge and familiarity of different languages, globalization and related technological revolution have transformed the manner in which information in the contemporary day is produced and perceived (Abdallah, 2011). The advent of the internet and related online technology has caused a paradigm shift in the field of translation from the utilization of printed materials to the use of digital translation and interpretation material (Drugan \& Chris, 2011). The popularity of digital translation information is accentuated by the advantages associated to it, for example easy accessibility and flexibility through technology such as computers (Baker, 2008). Apart from causing translators and interpreters to increasingly adopt digital set-ups in textual productions, Malmkjaer (2005) posits that technological developments influence translators to carry out their work through the use of computerized devices such as translation memory databases and automatic translation systems (Venuti, 1998).

The increased use of technological developments in the field of translation has led to the emergence of the term localization to refer to the process of translation. The main reason for this is the fact that many translators currently adapt software, websites and product documentations to carry out their translation exercises (Abdallah, 2011). Moreover, the incorporation of advanced technology in the process of translation is characterized by increased use of electronic tools such as electronic mail and instantly updated digital thesaurus which make it difficult for translation procedures to be carried out by a team (Koskinen, 2000).

There are current different types of technological advancements which are currently applied in the field of translation. The most popular include crowdsourcing, machine translation, translation management systems and translation memories (Baker, 2011). Crowdsourcing refers to a type of community lobbied translation which is utilized by large online groups based on sites such as Facebook, TED and Twitter (Baker \& Maier, 2011). This 
form of translation is commonly perceived as a suitable substitute for machine translation. Despite the prevalent use of technological developments in the field of translation, and their perceived usability benefits in presenting readers with a general understanding of content in foreign languages, Pym (2011) argues that the "text generated by such software can in no way be considered as the equivalent of a true translation" (p. 5). The implication of this statement is that translated text generated from software can only be perceived as true translation after it has been revised by a professional translator (Pym, 2011).

Interestingly, the translation market is changing much faster that the functions of translators as well as the tools that they use (Munday, 2001). The technologies and techniques of communication have evolved; despite this, the role fulfilled by translators has not changed much. In real essence a majority of translators in the contemporary day do not support the notion of engaging in real time translation since they are more used to investing significant amounts of time in carefully researching translation terminologies and reviewing their work in similar to all other writers (Venuti, 1998).

\section{Translation and Ethics}

There are several theories and models upon which the ethics of translation is based. According to Pym (2001), for example, the conventional ethics of translation is founded upon the concept of fidelity. According to the notion of fidelity, the translator is expected to remain faithful to the source author and source text as well as to the intentions of meanings communicated by the source author and text (Baker, 2011). In addition to being concerned with individual translators as related to individual texts and/or authors, the notion of fidelity also acknowledges that individual translators are preferably expected to depict faithfulness to the source facet of business rather than the target or receiver side (Baker, 2008). Apart from these two limitations, the translator has restricted scope for autonomy action.

It is however noteworthy that although it is still considered to be a relevant aspect of the social preconception of a translator's functions in the present day, the ethics of fidelity is no longer fashionable (Drugan \& Chris, 2011). The decline popularity of fidelity ethics has been caused by several factors particularly the fact that translation projects in the contemporary day are increasingly carried out in groups of technology engineers, terminologists, revisers, terminologists and translators (Abdallah, 2011). A second factor is that an increased number of translation products originate from authorless texts that are produced successfully by teams for example those produced in European Union institutions. The implication of this factor is there is no single author to whom a translator may be faithful.

Chesterman (2001) asserts that there are four main theories which underpin the field of translation and ethics. The first theory places preeminence on representation; the focus here is to examine the manner in which the target text reflects the source text or its author. The second model places focus on norms; the emphasis of this theory is on examining if translators behave or act in an expected standard way (Kastberg, 2007); thirdly is the theory focused on services; the preeminence under this theory is on whether translators and clients act in an ethical manner towards each other. The third model which focuses on communication places importance on the manner in which translations operate when confronted with the Other (Chesterman, 2001). Chesterman (ibid, p. 145) further argues that if a translator is to make the best ethical decision in all their translations and related activities they must possess certain virtues; the most important virtue is the desire by the translator to make the right decision and seek excellence in their career of translation (Baker, 2011). This is a useful contribution in the field of translation and ethics because it accentuates the importance of acknowledging that translators may be influenced by the ethical or unethical behavior of others around them and that the concept of translation ethics may be described in regards of translators seeking perfection in the practice of translation (Drugan \& Chris, 2011).

In explaining the issue of translation and ethics, Baker (2011) posits that the philosophies of Kantian rule-based ethics and Utilitarianism may be used to describe the ethical decisions that interpreters and translators are confronted with in their lines of duty. According to Baker (ibid) there is a difference between the codes of conduct and ethics which guide the behaviors of professionals in different field. Baker argues that "ethics is about the stream of life rather than just its turbulent moments" and that "many default choices that do not necessarily give rise to conscious decision-making can have important ethical implications" (p. 277). The different contributions made by authors such as Baker and Chesterman regarding ethics of translation are fundamental in forming a basis on which the ethics of technology or machine translation may be examined. Such contributions respond to the basic issues in the communication process of different agents, and examine the notion that influential interests who share translation resources are ethically obligated to the agents whose intellectual production is re-used (Abdallah, 2011). 


\section{Technology and Translator Ethics}

Recent technology is currently perceived as raising urgent ethical dilemmas regarding the role of a translator as an editor or re-creator of translated content (Baker, 2008). In fact, the prevalent use of emergent technology in the process of translation brings about several ethical questions which are seldom discussed in classroom settings (Floros, 2011). Furthermore the use of technology such as automatic translation systems in the field of translation and interpretation require translators to develop sets of new technical skills and competencies which they currently lack. Some important competencies include management of content translated through computerized technology and skills required to successfully manipulate diverse translation software programs (Goodwin, 2010).

Another way in which technological developments and advancements witnessed in the present day influence the ethical position of the translator is in regards to the relationship between source audiences/texts and target audiences/texts; for many decades now the correspondence between source and target has remained a controversial issue (Baker, 2008). The ethical implication of this controversy for translators is exacerbated by the fact that it is at the heart of the concept of machine translation thus causing ambiguity regarding the function of the translator (Goodwin, 2010). The use of emergent technologies in translation supports the recovery of the source by machines and thus undermines the tasks of post-editing, interpretation and reconfiguration of meanings in the target language that is commonly carried out by human translators (Baker, 2011). The recovery of source by machines in translation processes also poses an ethical dilemma regarding the position of the translator due to the risk of the translator's work being concealed or overshadowed by the work of the machine in the view of clients.

The different emergent technologies in the field of translation affect the ethical position of translators in different ways. Although the technology of crowdsourcing, for example, is instrumental in bridging the digital divide currently experienced globally, the ethics upon which it is founded are perceived to be controversial based on its effects on the translation profession and the impacts it has on the type of relationship it established between translators and their clients (Baker \& Maier, 2011). It is however noteworthy that while some translators view crowdsourcing technologies such as Twitter and Facebook as being unethical and adverse for the translation career, there are others who perceive it has positively impacting the profession (McDonough-Dolmaya, 2012). The ethics of machine or technology-based translation is comprised of different agents such as, the writers of original/source texts, consumers and commissioners of machine translation, translators whose content is used in information machine translation, post-editors and trainee translators (Baker, 2011). There are thus a variety of ethical considerations which arise from the examination of these different stakeholders.

The technology of translation memories is founded upon the practice of amassing and storing translation solutions which may be reprocessed as needed by use of automation (Drugan \& Chris, 2011). Although this translation technology is beneficial in regards to increased efficiency and productivity by translators, the terminological databases it establishes pose ethical dilemmas for the translator in similar manner to the case of translation machine applications, the design and manufacture of translation memory programs in the industry is aimed at attainment of cost and time benefits thus resulting in a word-replacement form of translation which might interfere with the intended meaning of the original/source text (Abdallah, 2011). The ethical position of the translator in this regard is further shaken by the fact that although translation memory programs may result increase consistency, consistency does not ascertain comprehension. The main reason for this is that it is not uncommon for a text to be typified by excellent terminological coherence yet lack sensibility for the target audience (Baker, 2008).

The issue of accuracy and accountability by the translator when making use of translation technology or software is another pressing ethical issue. According to Abdallah (2011) the issue of software errors in the contexts in which translation software is used is inevitable. There is currently no perfect machine translation system which can translate any pair of languages with one hundred percent accuracy (Baker, 2011). When translators make use of translation technology, therefore, they are tasked with the ethical duty of making it clear to their clients that the translations they produce cannot be perfect although the translation machines or technologies that are used have been studied computationally for years (Cacchiani, 2006). In addition to this, translators are still confronted with the dilemma of determining when translation machines or technologies have attained a level of linguistic precision or coverage that may be perceived as satisfactory or good enough. While they must not exaggerate or overstate the accuracy of translation technologies, translators and interpreters may also not understate the benefits of such technology (Floros, 2011).

Another ethical issue in regards to the positional of a translator brought about by the use of technology in 
translation is that technology reduces the process of translation into a primitive type of fidelity (Baker, 2008). Although technological developments are useful in enabling the translator to get segment texts into different fragments and rid of visible formatting, translators have to ensure that they match work pairs accurately. After matching up and saving the pairs, they become unidentified in similar manner to the translator, end user and producer of the original text. In this sense, the proliferation of technology in the field of translation reduces the process to a primitive sense of fidelity (Pym, 2001).

The use of technology in translation affects the ethical position of the translator because technology is rarely perfect and it is crucial for translators to remain sensitive of such imperfections (Floros, 2011). The most important issue, therefore, in the use of emergent technology in translation processes is that the application of such technology, for example translation memories and machine translation programs, means that the only active role played by the translator is making final touches to the machine translated content in order to make it comprehensible by the target audience. In such cases clients perceive the machine as having done all the translation and the translator was merely engaged in editing the final text. Such an impression-that machines are able to translate texts- negatively influences the perception of translators and the translation career (Goodwin, 2010).

On the other hand, it is worth noting that technology in the contemporary day is not an option in the professional context; on the contrary, it is a necessity. Almost all forms of translation are supported by some form of technology, particularly computers (Cacchiani, 2006). The different benefits associated with technology on numerous levels are undeniable Translation memories, for example, are beneficial in carrying out the most repetitive activities I order to allow translators adequate amounts of times to concentrate on the most important and creative elements of translation (Hatim \& Mason, 1997). It is thus fundamental to acknowledge that the intelligent use of technology in processes of technology is that which allows for and supports the efforts of translators on where they are required the most (Baker, 2011). Furthermore, investments in particular technologies may be crucial for translators if they are to shift from one segment of the translation market to another. This kind of shift commonly occurs when clients present translators with work that demands the knowledge or use of particular technology or certain software (Baker, 2008). In such cases the translator has to learn speedily in order to ensure that they have the skills and tools they require for the job.

\section{Conclusion}

This essay has examined and discussed the effects that recent developments in technology have on the ethical position of the translator. The technological developments have reconstructed the position of translators and illuminated the susceptibility of translators and the influence they have on the lives of their clients. The implication of such developments is that it is vital for interpretation and translation schools to adopt different strategies and approaches to the education they expose students of translation to. It is fundamental for all relevant authorities in the field of translation and interpretation to reevaluate that which constitutes ethical behavior in the field of interpretation and translation, as well as the kind of training that translation and interpretation novices in institutes of higher education should be exposed to. Furthermore, as translators exploit translation capabilities offered by machines, they must consider of the benefits of the technology are worth the cost of their translation work being downgraded as simple copy editing work.

\section{References}

Abdallah, K. (2011). Towards empowerment: Students' ethical reflections on translating in production networks. The Interpreter and Translator Trainer, 5(1), 129-154. http://dx.doi.org/10.1080/13556509.2011.10798815

Baker, M. (2008). Ethics of renarration: Mona Baker is interviewed by Andrew Chesterman. Cultus, 1(1), 10-33.

Baker, M. (2011). In other words. London: Routledge.

Baker, M., \& Maier, C. (2011). Ethics in interpreter \& translator training: Critical perspectives. The Interpreter and Translator Trainer, 5(1), 1-14.

Cacchiani, S. (2006). Dissimilarities between patient information leadlets in Britain Italy: Implication for the translator. New Voices in Translation Studies, 2(1), 28-43.

Drugan, J., \& Chris, M. (2011). Bringing ethics into translator training: An integrated, inter-disciplinary approach. The Interpreter and Translator Trainer, 5(1), 189-211. http://dx.doi.org/10.1080/13556509.2011.10798817

Floros, G. (2011). Ethic-less theories and ethical practices: On ethical relativity in translation. The Interpreter and Translator Trainer, 5(1), 65-92. http://dx.doi.org/10.1080/13556509.2011.10798812 
Goodwin, P. (2010). Ethical problems in translation: Why we might need Steiner after all. The Translator, 16(1), 19-42. http://dx.doi.org/10.1080/13556509.2010.10799292

Hatim, B., \& Mason, I. (1997). The Translator as a Communicator. London/New York: Routledge.

Kastberg, P. (2007). Cultural issues facing the technical translator. Journal of Specialized Translation, 8(1), 104-109.

Koskinen, K. (2000). Beyond ambivalence: Postmodernity and the ethics of translation. Tampere: University of Tampere.

Malmkjaer, K. (2005). Linguistics and the language of translation. Edinburgh: Edinburgh University Press.

McDonough-Dolmaya, J. (2012). Analyzing the crowdsourcing model and its impacts on public perceptions of translation. The Translator, 18(2), 167-191. http://dx.doi.org/10.1080/13556509.2012.10799507

Munday, J. (2001). Introducing translation studies: Theories and applications. London/New York: Routledge.

Pym, A. (2001). The return to ethics in translation studies. The Translator, 7(2), 129-138. http://dx.doi.org/10.1080/13556509.2001.10799096

Pym, A. (2011). What technology does to translating. Translation and Interpreting, 3(1), 1-9.

Venuti, L. (1998). The scandals of translation: Towards an ethics of difference. London/New York: Routledge. http://dx.doi.org/10.4324/9780203269701

\section{Copyrights}

Copyright for this article is retained by the author(s), with first publication rights granted to the journal.

This is an open-access article distributed under the terms and conditions of the Creative Commons Attribution license (http://creativecommons.org/licenses/by/4.0/). 